\title{
8
}
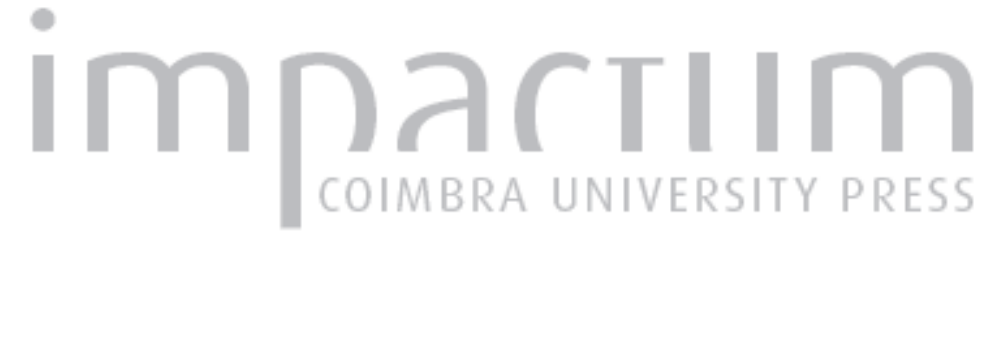

\section{O risco de inundação na cidade de Amarante (Norte de Portugal): contributo metodológico para o seu estudo}
Autor(es):
Costa, Francisco Silva
Publicado por: Associação Portuguesa de Riscos, Prevenção e Segurança
URL persistente:
URI:http://hdl.handle.net/10316.2/36152
DOI:
DOI:http://dx.doi.org/10.14195/1647-7723_16_9
Accessed : $\quad$ 26-Apr-2023 11:53:00

A navegação consulta e descarregamento dos títulos inseridos nas Bibliotecas Digitais UC Digitalis, UC Pombalina e UC Impactum, pressupõem a aceitação plena e sem reservas dos Termos e Condições de Uso destas Bibliotecas Digitais, disponíveis em https://digitalis.uc.pt/pt-pt/termos.

Conforme exposto nos referidos Termos e Condições de Uso, o descarregamento de títulos de acesso restrito requer uma licença válida de autorização devendo o utilizador aceder ao(s) documento(s) a partir de um endereço de IP da instituição detentora da supramencionada licença.

Ao utilizador é apenas permitido o descarregamento para uso pessoal, pelo que o emprego do(s) título(s) descarregado(s) para outro fim, designadamente comercial, carece de autorização do respetivo autor ou editor da obra.

Na medida em que todas as obras da UC Digitalis se encontram protegidas pelo Código do Direito de Autor e Direitos Conexos e demais legislação aplicável, toda a cópia, parcial ou total, deste documento, nos casos em que é legalmente admitida, deverá conter ou fazer-se acompanhar por este aviso.

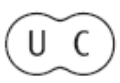




\section{territorium}

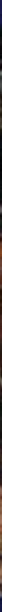

16

Revista da Associação Portuguesa de Riscos, Prevenção e Segurança 2009 


\section{O RISCO DE INUNDAÇÃO NA CIDADE DE AMARANTE (NORTE DE PORTUGAL) : CONTRIBUTO METODOLÓGICO PARA O SEU ESTUDO*}

Francisco Silva Costa

Instituto de Ciências Sociais, Universidade do Minho

costafsageografia.uminho.pt

\section{RESUMO}

A partir do estudo das principais cheias no rio Tâmega (bacia do Dauro), pela sua passagem na cidade de Amarante, pretende dar-se um contributo sobre alguns aspectos metodológicas a considerar no cumprimento da Directiva 2007/60/CE do Parlamento Europeu e do Conselho, de 23 de Outubro de 2007, que tem, por abjectivo, "reduzir o risco e as consequências negativas das inumdações na União Errropeia".

Palavras chave: Directiva 2007/60/CE, cheias, grau de exposição.

\section{RÉSUMÉ}

Avec l'étude des grandes inondations de la rivière Tâmega (bassin du Darro) par son passage dans la ville d'Amarante, on vise à donner une contribution sur certains aspects méthooblogiques à prendre en considération dans le respect de la directive 2007/60/CE du Parlement Européen et du Conseil du 23 octobre 2007, qui a, par abjectif, "réduire les risques et les conséquences négatives des inondations dans l'Union eurquéenne".

Mbts-clé: Directive 2007/60/CE, crues, degré d'exposition.

\section{ABSTRACT}

From the study of major floods in the river Tâmega (Darro basin) by its passage in the town of Amarante, aims to give a contribution on some methodblogical aspects to be considered in compliance with Directive 2007/60/ EC of the European Council of 23 October 2007, that has, by objective, "reduce the risk and the negative consequences of floods in the Errropean Union.

Key words: Directive 2007/60/EC, floods, degree of exposure.

\footnotetext{
* Commicação apresentada ao V Encontro Nacional e I Congresso Intemacional de Riscos.
} 


\section{Introdução}

A posição comm aprovada pelo Conselho em 23 de Novembro de 2006, tendo em vista a aprovação de uma directiva do Parlamento Europeu e do próprio canselho relativa a avaliação e gestão dos riscos de inundações, pressupõe que "as cheias são fenámenos naturais que não podem ser evitadas" e reconhece a necessidade de reduzir o risco de consequências prejudiciais associadas às inundações, especialmente para a saúde e a vida humanas, o ambiente, o património cultural, as actividades económicas e as infra-estnuturas.

A União Europeia reconhece assim a necessidade de um planeamento das medidas de protecção das cheias ao nível daloacia hidrográfica que vá ao encontro da existência das diferenças na percepção e na aceitação do risco de cheia entre os Países-Membros.

\section{Ponto de Partida: a Directiva 2007/60/CE (Directiva relativa à Avaliação e Gestão dos Riscos de Imundações - DAGRI)}

A Directiva 2007/60/CE do Parlamento Europeu e do Conselho, de 23 de Outubro de 2007, tem por objectivo elaborar um quadro para a análise e a gestão dos riscos ligados às inundações para a saúde humana, o ambiente, o património cultural e as actividades económicas. Exigirá um estudb inicial dos riscos de inundação, a cartografia das inundações em todas as zonas com risco significativo de inundação, a coordenação no interior de bacias hidrográficas comuns e a elaboração de planos de gestão dos riscos de imundação graças a um amplo processo de participação.

São vários os tipos de inundações que ocorrem em toda a commidade: cheias de origem fluvial, cheias repentinas, inundações urbanas e inundações marítimas em zonas costeiras. Os danos causados pelas inundações podem também variar entre países e regiões da Comunidade. Por esse motivo, a DAGRI aponta para objectivos de gestão dos riscos de inundaçães baseados nas particularidades locais e regionais, fixados pelos próprios Estados-Membros.

A fim de dispor de um instrumento de informação eficaz, bem como de uma base valiosa para estabelecer prioridades e para tomar decisões técnicas, financeiras e políticas ulteriores emmatéria de gestão de riscos de inundaçães, a DAGRI reconhece a necessidade da elaboração de cartas de zonas inundáveis e de cartas de riscos de inundações indicativas das potenciais consequências prejudiciais associadas a diferentes cenários de inundações. No sentidb de evitar e reduzir os impactos negativos das inundações nas zonas em causa, a DAGRI prevê a elaboração de planos de gestão dos riscos de inundações que deverão ter em conta as características próprias das zonas a que se referem e prever soluções específicas para cada caso, de acordo com as necessidades e prioridades de tais zonas, assegurandb ao mesmo tempo uma coordenação adequada no interior das regiões hidrográficas.

Dada a diversidade da União Europeia em termos geográficos, hidrológicos e de ordenamento do território, a DAGRI dá bastante flexibilidade aos Estados-Membros para determinarem os objectivos para a gestão dos riscos de inundação, as medidas a adoptar para atingir esses objectivos e os calendários para implementar os planos de gestão dos riscos de inundação.

\section{Análise prel iminar das riscas de inumdação}

A DAGRI refere-se ao conceito de «inundação» como "a cobertura temporária por água de uma terra normalmente não coberta por água. Inclui as cheias ocasionadas pelos rios, pelas torrentes de montanha e pelos arrsos de água efémeros mediterrânicos, e as inundações ocasionadas pelo mar nas zonas costeiras, e pode excluir as inundações com origem em redes de esgotos."

Tendo por base esta definição, a análise prel iminar das riscos de inundações prevista na DAGRI deverá incluir, pelomenos, os seguintes elementos:

- as cartas da região hidrográfica à escala apropriada, incluindbas sub-bacias hidrográficas;

- uma descrição e avaliação das inundações ocorridas no passado que tenham tido impactos negativos importantes, nos casos em que continue a existir uma probabilidade significativa de inundações semelhantes voltarema ocorrer no futuro;

- uma descrição das imundações significativas ocorridas no passado, sempre que se possam prever consequências prejudiciais significativas resultantes da ocorrência de inundações semelhantes no futuro;

- uma estimativa das potenciais consequências prejudiciais das futuras inundações para a saúde humana, o ambiente, o patrimánio arltural e as actividades económicas. Neste âmbito, devem ser considerados, tanto quanto possível, o impacto da variabi lidade cl imática na ocorrência de inundações, bem como questões relacionadas com a topografia, a posição dos cursos de água e as suas características hidrológicas e geomorfológicas gerais, incluindb as planícies aluviais enquanto zonas de retenção natural, a eficácia das infra-estnuturas artificiais existentes de protecção contra as inundaçães, e 
a dinâmica, a longo prazo, das populações e das actividades económicas.

\section{A carta de zonas inundáveis}

Segundo a DAGRI, as cartas de zonas inundáveis cobrem as zonas geográficas susceptíveis de ser inundadas, de acordo com os seguintes cenários:

a) Fraca probabilidade de cheias au cenários de fenómenos extremos;

b) Probabiliclade média de cheias (periodicidade provável igual au superior a 100 anos) ;

c) Probabilidade elevada de cheias, quando aplicável.

Para cada umdbs cenários referidbs, devem indicar-se os seguintes elenentos:

a) Amplitude da inundação;

b) Profundidades de água ou nível de água, quando aplicável;

c) Quandb aplicável, igualmente, a velocidade da corrente qu o caudal da cheia correspondente.

\section{A carta de riscos de inumdaçães}

A DAGRI refere-se ao conceito de «risco de inundação» como "a combinação da probabilidade de inundações e das suas potenciais consequências prejudiciais para a saúde humana, o ambiente, o património cultural e as actividades económicas" . Tendb em conta esta definição, as cartas de riscos de inundaçães devem indicar as potenciais consequências prejudiciais associadas às inundações nos cenários referidos, expressos en termos de:

a) número indicativo de habitantes potencialmente afectadbs;

l) tipo de actividade económica da zona potencialmente afectada;

d) instalaçães, referidas no anexo I da Directiva 96/61/CE do Conselho, de 24 de Setembro de 1996, relativa à prevenção e controlo integrados da poluição, que possam causar poluição acidental em caso de inumdações, e zonas protegidas identificadas nos pontos i) , iii) e v) da secção 1 do anexo IV da Directiva 2000/60/CE, potencialmente afectadas;

d atras informaçães que os Estadbs-Menbros consideremúteis, como a indicação das zonas ande podem ocorrer inundaçães que arrastem um elevadb volume de sedimentos e detritos, e informações sobre atras fontes importantes de poluição.

\section{Os planos de gestão das riscas de immdaçães}

As conclusões da análise preliminar dos riscas de inundações devem permitir uma leitura sob a forma de um mapa sumário da bacia hidrográfica ou da unidade de gestão, delineando as zonas que são dbjecto do plano de gestão das riscos de inundações. Assim, combase nas cartas de zonas inundáveis e nas cartas de riscos de inundações, bem como nas conclusões que podem ser extraídas dessas cartas, são identificados vários elementos a prever nos primeiros planos de gestão dos riscos de inumdações, sendb de referir a descrição das dojectivos adequadbs de gestão dos riscos de inundaçães e o sumário das medidas destinadas a atingir os objectivos adequados de gestão das riscos de inundaçães.

\section{Um contributo metodológico para o estudo das inumdações em Amarante}

O interesse pelo conhecimento do regime das cheias e das áreas inundáveis, assim como dos processos que as condicionam, foi sempre um domínio privilegiado da investigação, em geografia física. Infel izmente, no que respeita ao rio Tâmega, nomeadamente às inundações na cidade de Amarante, os estudos estão ainda numa fase inicial (PEDROSA e COSTA, 1999).

Identificação das zonas com riscos potenciais significativos de inundaçães

A DAGRI aponta a identificação e análise das zonas com riscos potenciais significativos de inumdações, a partir dum conjunto de informaçães, a seguir descriminados.

\section{Testemnhos históricos e referências jomalísticas}

Destacam-se aqui os jomais locais, omais antigo, "Flor de Tâmega", e os mais recentes, "Jomal de Amarante", "Repórter do Marão" e "Tribuna de Amarante" . A consulta destes jomais permitirá a criação duma base de dados com notícias associadas às cheias, nomeadamente aquelas que afectaram de forma mais significativa a cidade de Amarante (figs. 1 e 2) e estabelecer uma cronologia dos principais acontecimentos ligados às inundações (Qtiro I) .

Existem outros elementos a ter em conta e a recolher, nomeadamente, os registos fotográficos (fot. 1) , a alguns aspectos da arquitectura local (fot. 2) , e mesmo os relatos dos habitantes locais mais afectados, através de entrevistas e inquéritos.

\section{Marcas de cheias}

São várias as placas que marcam o nível da altura das principais inundações da cidade de Amarante, 1909, 1939, 1962 e 2001, localizando-se ao longo 
Queda de água causa prejuízos

$A$ forte queda de água que no passado dia 4 eclodiu causon grandes inundaçбes em loda regilo de Amarante, dando origem a elevados prejuizos.

Em algumas zonas da cidade as ruas transformaram-se autênticos rios. Nos largos de Sant Luzia e do Arquinho algumas lojas foram inundadas por ámas bem ma cheirosas porque até as conduas do esgotos transbordaram pelas respectivas tampas. Os bombeiros. serviços da CAmara e algun populares logo se mobilizaram no sentido de obstar mais graves

Fig. 1 - Notícia do Jomal "Flor do Tâmega", do dia 10.12.92.

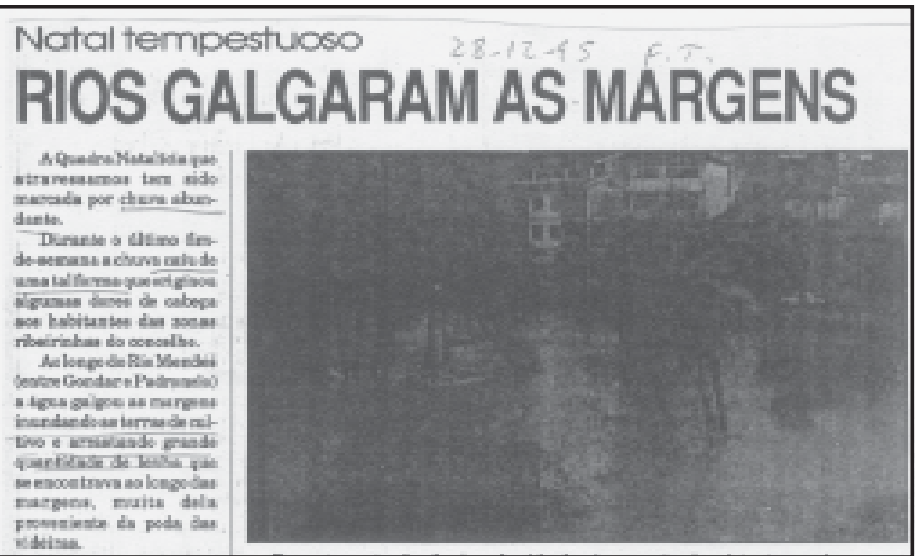

Fig. 2 - Notícias do Jornal "Flor do Tâmega", do dia 28.12.95.

Qundro I - Algumas das principais inundações de Amarante depois de 1960.

\begin{tabular}{|c|c|c|}
\hline DATA & $\begin{array}{c}\text { ÁREA } \\
\text { AFECTADA }\end{array}$ & DESCRIÇÃO \\
\hline NOV 1960 & $\begin{array}{l}\text { - Parte baixa } \\
\text { da cidade }\end{array}$ & $\begin{array}{l}\text { - Chuvas torrenciais...Navegou-se na Rua } 31 \text { de Janeiro até quase à Ponte de S. Gonçalo...O rio } \\
\text { tentou por } 3 \text { vezes invadir este local. }\end{array}$ \\
\hline JAN 1961 & & - Chuva há 4 meses. \\
\hline ABR 1962 & $\begin{array}{l}\text { - Parte baixa } \\
\text { da cidade }\end{array}$ & $\begin{array}{l}\text { - Chuva contínua...Inundação que obrigou a fazer o trajecto da parte alta para a baixa por meio de } \\
\text { barcos...As águas do rio atingiram as pedras angulares dos } 3 \operatorname{arcos} \text { da Ponte } \mathrm{S} \text {. Gonçalo...Caudal } \\
\text { superior a } 2000 \mathrm{~m} 3 / \mathrm{s} \text {. }\end{array}$ \\
\hline JAN 1963 & $\begin{array}{l}\text { - Parte baixa } \\
\text { da cidade }\end{array}$ & - Chuvas fazem crescer o rio até às lojas destinadas aos arrumos. \\
\hline $\begin{array}{l}\text { JAN/FEV } \\
1966\end{array}$ & $\begin{array}{l}\text { - Lg. } \\
\text { Conselheiro } \\
\text { António } \\
\text { Cândido }\end{array}$ & $\begin{array}{l}\text { - Chuvas constantes...O rio atingia uma elevada altitude, galgando as oficinas e inundando o Lg. } \\
\text { Conselheiro António Cândido. }\end{array}$ \\
\hline MAR 1969 & $\begin{array}{l}\text { - Rua } 31 \text { de } \\
\text { Janeiro e } \\
\text { Av. Beira- } \\
\text { Rio }\end{array}$ & $\begin{array}{l}\text { - Chuvas diluvianas constantes...Galgou a Av. Beira-Rio e obrigou a fazer a passagem em parte da } \\
\text { Rua } 31 \text { de Janeiro de barco...O rio Tâmega baixou lentamente ao seu leito normal. }\end{array}$ \\
\hline FEV 1972 & & - O Tâmega andou nas ruas \\
\hline $\begin{array}{l}\text { MAR e } \\
\text { DEZ } \\
1978\end{array}$ & $\begin{array}{l}- \text { Rua } 31 \text { de } \\
\text { Janeiro e } \\
\text { Lg. } \\
\text { Conselheiro }\end{array}$ & $\begin{array}{l}\text { - } 3 \text { cheias quase seguidas com prejuízos materiais...Inundação de todas as casas da parte baixa da } \\
\text { cidade...Lago no Lg. Conselheiro criado pela subida das águas através dos esgotos...O rio subiu } \\
\text { cerca de } 7 \text { metros. }\end{array}$ \\
\hline JAN 1979 & $\begin{array}{l}\text { - Parte baixa } \\
\text { da cidade }\end{array}$ & $\begin{array}{l}\text { - Cerca das } 14 \text { horas, a PSP foi alertada por Mondim de Basto que o rio Tâmega estava a sofrer uma } \\
\text { forte cheia. Por volta das } 15 \text { horas, as águas começaram a subir à média de um metro por hora, } \\
\text { atingindo o nível da cheia de Abril de } 62 \text {. Eram cerca de } 22 \text { horas quando o Tâmega começou a } \\
\text { baixar lentamente. }\end{array}$ \\
\hline JAN 1982 & $\begin{array}{l}\text { - Lg. } \\
\text { Conselheiro }\end{array}$ & - Faltava apenas um palmo para o Tâmega invadir o Lg. Conselheiro. \\
\hline OUT 1987 & $\begin{array}{l}\text { - Praias } \\
\text { fluviais }\end{array}$ & - A água cobriu a Praia Aurora e até meio das árvores da Praia do Areal. \\
\hline DEZ 1992 & $\begin{array}{l}\text { - Em toda } \\
\text { cidade }\end{array}$ & $\begin{array}{l}\text { - Forte queda de água...Grandes inundações provocadas pelo transbordamento através das condutas } \\
\text { dos esgotos em consequência do rápido aumento do caudal do rio Tâmega. }\end{array}$ \\
\hline $\begin{array}{l}\text { DEZ/JAN } \\
1995 / 96\end{array}$ & $\begin{array}{l}\text { Parte baixa } \\
\text { da cidade }\end{array}$ & $\begin{array}{l}\text { - Inverno chuvoso...Temporal com uma hora de chuvas torrenciais contínuas...O rio ameaçou o Lg. } \\
\text { Conselheiro e a Rua } 31 \text { de Janeiro, tendo invadido o jardim Amadeu Sousa Cardoso. A ribeira de } \\
\text { São Lázaro galgou as margens. }\end{array}$ \\
\hline $\begin{array}{l}\text { MAR } \\
2001\end{array}$ & $\begin{array}{l}\text { Em toda a } \\
\text { cidade }\end{array}$ & $\begin{array}{l}\text { - Subida do rio mais de } 10 \text { metros; derrocadas de muros e de terras; estabelecimentos comerciais } \\
\text { completamente destruídos e sujos de lama; bombas de gasolina arrancadas; Ínsua dos Frades ficou } \\
\text { submersa. }\end{array}$ \\
\hline
\end{tabular}

(Fonte: Gaves e COSTA, 2004) 


\section{territorium 16}

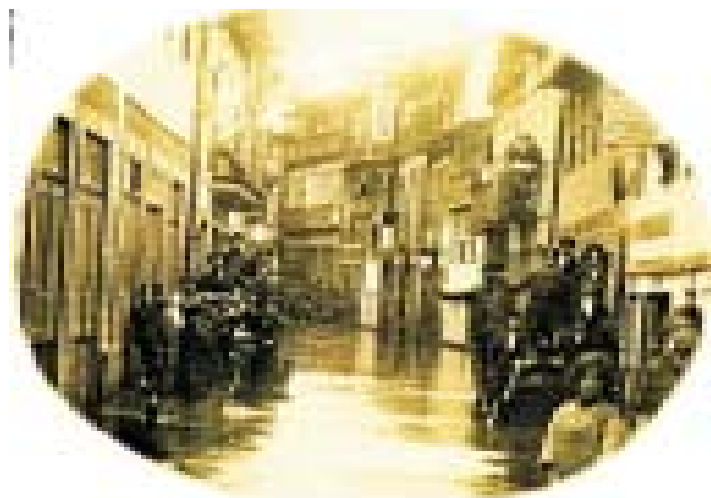

Fot. 1 - Cheia de 1939.

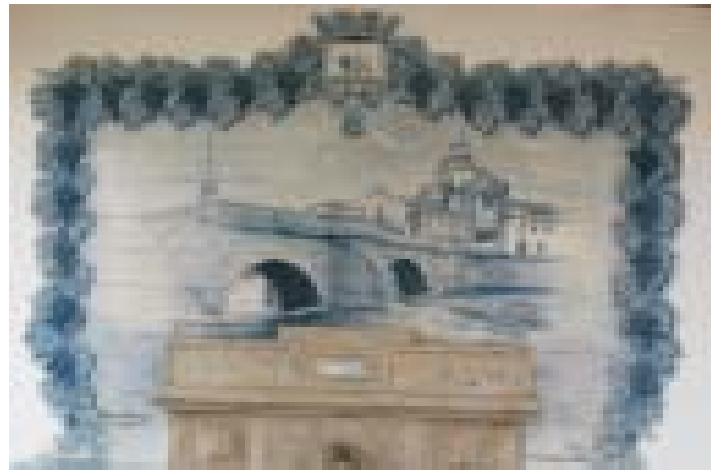

Fot. 2 - Painel de azulejo relativo à cheia de 1939.

da nua mais afectada por estas, a nua 31 de Janeiro, e no largo Conselheiro António Cândido. Trabalhos de topografia permitiram calcular a cota atingida por cada uma destas cheias, tendo em conta as alturas que estas atingemnos diferentes locais onde se encontramafixadas (fots. 3, 4 e5).

\section{Níveis máximas registados}

A evolução da altura das cheias é feita com rearso a duas escalas hidrométricas - uma situada na margem esquerda do rio Tâmega, cerca de 300 metros a jusante da Ponte de São Gonçalo (fot. 6) , a funcionar com um sensor de nível desde 2003 (estação 06I/05H, propriedade do INAG) e outra sobre o pilar mais próximo da margem direita da Ponta São Gonçalo (estação 06I/01H, extinta desde 1957, fot. 7) .

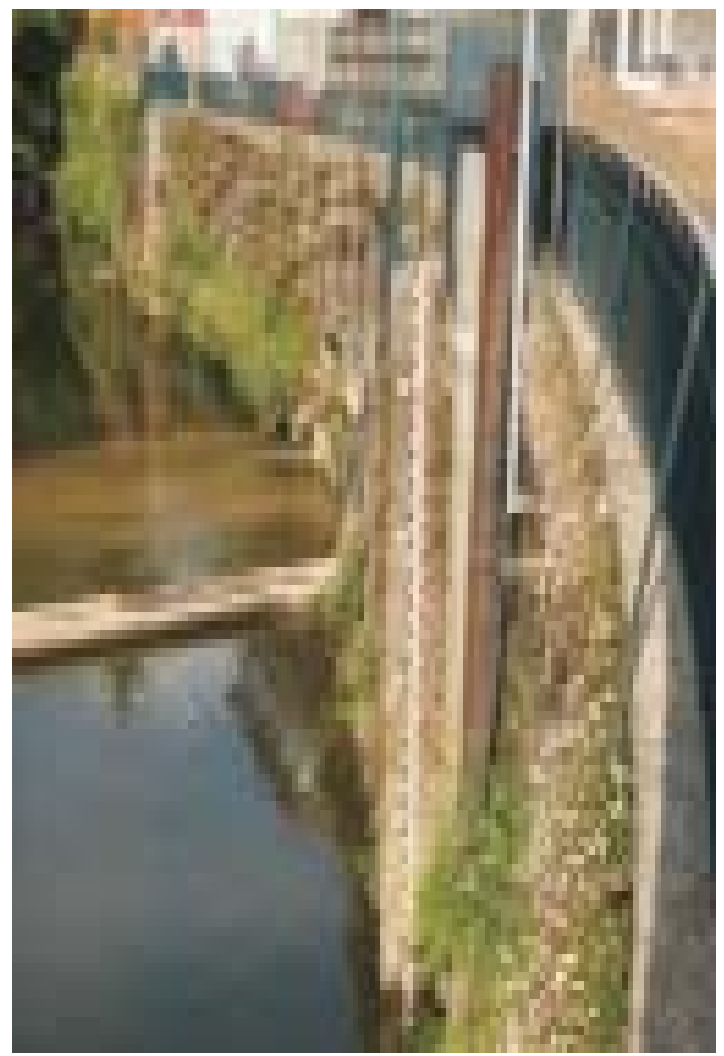

Fot. 6 - Escala hidrométrica de cepelos.

Seria, sem dúvida, importante reiniciar a actividade desta última, bem como montar novas escalas, nomeadamente na parte jusante da mesma ponte, e sobre um dos pilares da Ponte Nova, situada cerca de 500 metros para montante, por forma a doter alturas que permitissem inferir da importância dos factos locais na sua variabilidade.
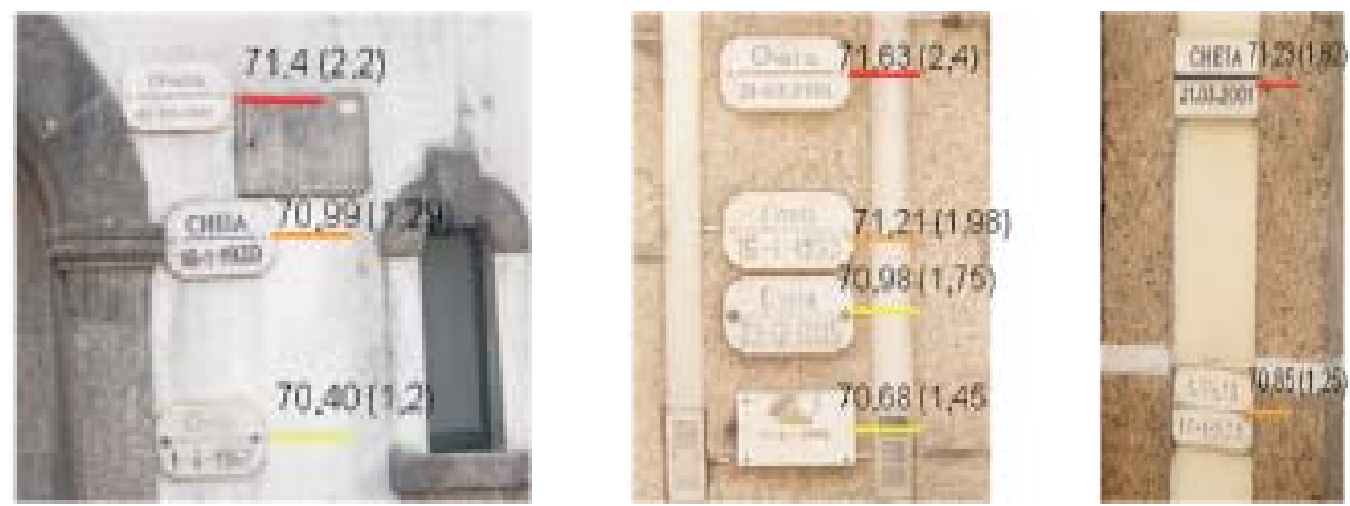

Fots. 3, 4 e 5-Nivel das cotas atingidas pelas principais cheias em Amarante e respectivas alturas. 


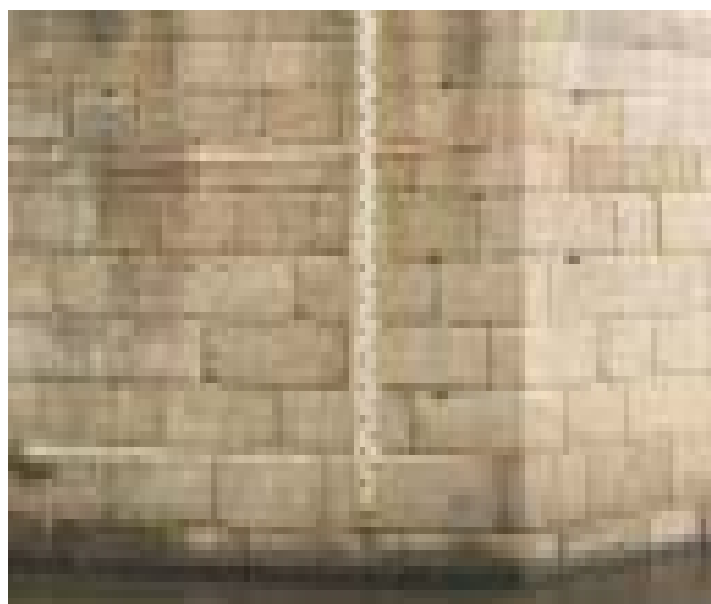

Fot. 7 - Escala hidrométrica de São Gonçalo.

Registos hidrométricas

Os registos relativos aos caudais são, sem đúvida, fundamentais na descrição e na explicação dos regimes de cheia. Tendo em conta a necessidade de encontrar séries suficientemente longas em termos temporais, e não sendo possível dbtê-las à escala local, são necessários as registos relativos a mais três estaçães, Fridão, 7 quilómetros a montante, Ponte de Canavezes, a jusante de Amarante. e Ponte de Cavez, situada a montante, já no concelho de Ribeira de Pena (Qurro II e fig. 3) .
Tendb em conta as características das locais ande estão instaladas estas estações hidrométricas, nomeadamente, no que diz respeito ao perfil do vale fluvial (fots. 8, 9, 10 e 11), serán necessário proceder à ponderação dos dados relativos a Fridão, Ponte de Canavezes e Ponte de Cavez, a partir da área drenada e por comparação com a de Amarante, por forma a validar toobs registos em função da local ização desta na cidade.

A consulta descritiva das cheias, commaiores efeitos no espaço unbano de Amarante, permite retirar algumas ilações que são reforçadas com a análise dos caudais médios diários, os máximos diários instantâneos e comos valores referentes às influências integrais mensais. A análise de cheias deve conduzir à estimativa dos picos de caudais de cheia e à sua frequência de ocorrência em cada secção transversal considerada (Pedrosa e Costa, 1999).

O caudal médio diário constitui a noção de base e o ponto de partida para estabelecer os caudais característicos, necessários para descrever o comportamento de um rio. No entanto, o caudal médio diário é só um reflexo do verdadeiro caudal máximo atingido no momento mais forte da cheia (o pico de cheia que é registado sob a designação de máximo instantâneo diário) . Fn cada ano, o rio atinge um caudal diário momentâneo máximo, independentemente de o facto causar ou não inundação (Pedrosa e Costa, 1999).

Quño II - Relação das estações hidrométricas.

\begin{tabular}{|c|c|c|c|c|c|}
\hline CÓDIGO & NOME & $\begin{array}{c}\text { ÁREA } \\
\text { DRENADA }\left(\mathrm{km}^{2}\right)\end{array}$ & CONCELHO & $\begin{array}{c}\text { ENTRADA } \\
\text { FUNCIONAMENTO } \\
\text { (CONVENCIONAL) }\end{array}$ & ESTADO \\
\hline $06 \mathrm{I} / 02 \mathrm{H}$ & $\begin{array}{c}\text { PONTE } \\
\text { CANAVEZES }\end{array}$ & 3163.33 & $\begin{array}{l}\text { MARCO DE } \\
\text { CANAVESES }\end{array}$ & 09-12-1955 & $\begin{array}{c}\text { EXTINTA 30- } \\
03-1988\end{array}$ \\
\hline $06 \mathrm{I} / 04 \mathrm{H}$ & $\begin{array}{l}\text { AMARANTE } \\
\text { (EDP) }\end{array}$ & 2846.2 & AMARANTE & 28-05-1985 & ACTIVA (EDP) \\
\hline 06I/03H & FRIDÃO & 2616.42 & AMARANTE & 07-10-1985 & ACTIVA (EDP) \\
\hline $04 \mathrm{~J} / 05 \mathrm{H}$ & PONTE CAVEZ & 1995.99 & $\begin{array}{l}\text { RIBEIRA DE } \\
\text { PENA }\end{array}$ & 24-10-1957 & ACTIVA (EDP) \\
\hline
\end{tabular}

(Fonte: INAG, 2009)

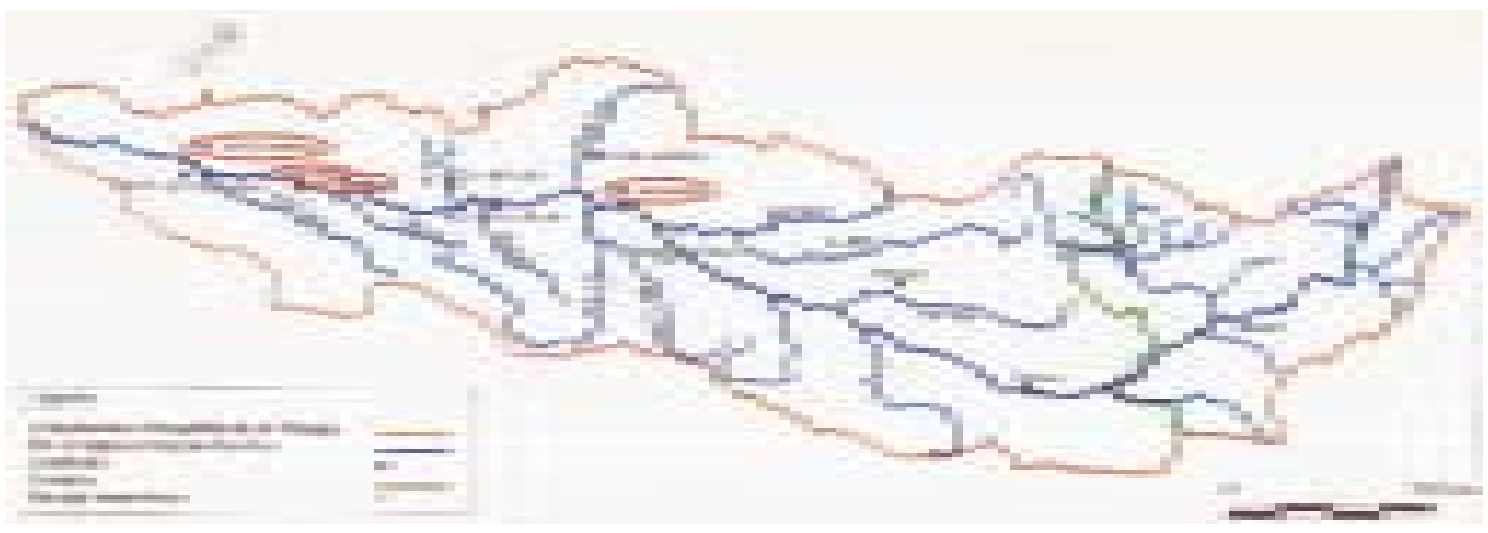

Fig. 3 - Localização das estações hidrométricas. 

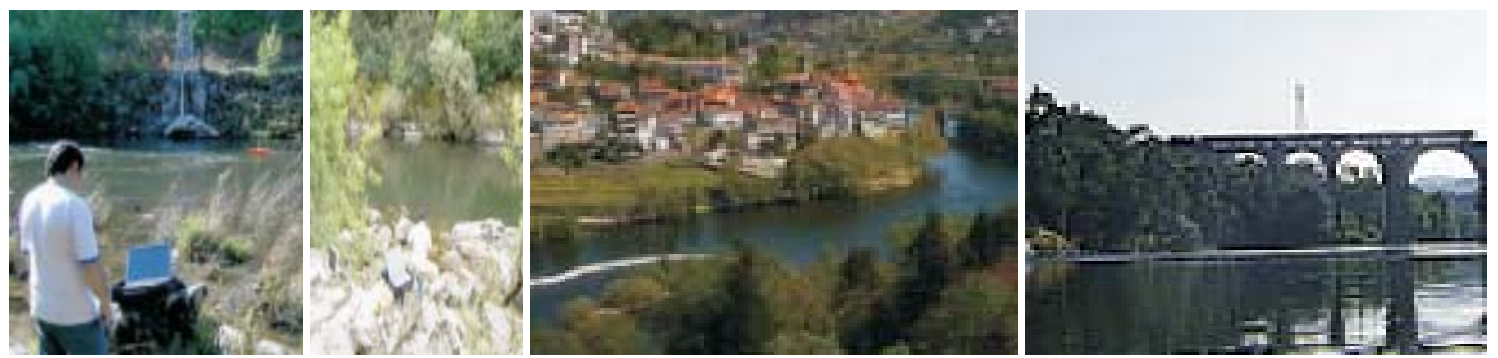

Fots. 8, 9, 10 e 11 - Local de implantação das estações hidrométricas de Ponte de Cavez, Fridão, Amarante e Ponte de Canavezes (Fots. INAG, 2009).

Para uma análise rigorosa do regime das cheias em Amarante será assim necessário recorrer aos máximos anuais instantâneos, que revelam os picos atingidos em cada ano (Qipro III), mas também aos caudais médios diários, que permitem uma caracterização temporal das mesmas (figs. 4 e 5) .

QuRRo III - Máximos amuais instantâneos nas estações hidrométricas de Ponte de Canavezes e Ponte de Cavez, no período 1960-1986.

\begin{tabular}{|c|c|c|c|c|c|c|c|}
\hline \multirow[b]{3}{*}{1960} & \multicolumn{3}{|c|}{ Ponte de Canavezes } & \multicolumn{4}{|c|}{ Ponte de Cavez } \\
\hline & Máx. diários inst. & & Ordenação & & Máx. diários inst. & & Ordenação \\
\hline & 1594 & 1962 & 1961 & 1960 & 1053 & 1966 & 1152 \\
\hline 61 & 936 & 78 & 1882 & 61 & 688 & 62 & 1082 \\
\hline 62 & 1961 & 72 & 1653 & 62 & 1082 & 69 & 1057 \\
\hline 63 & 1145 & 69 & 1640 & 63 & 660 & 60 & 1053 \\
\hline 64 & 712 & 60 & 1594 & 64 & 424 & 72 & 730 \\
\hline 65 & 1057 & 66 & 1553 & 65 & 575 & 81 & 711 \\
\hline 66 & 1553 & 79 & 1334 & 66 & 1152 & 79 & 702 \\
\hline 67 & 631 & 81 & 1296 & 67 & 377 & 61 & 688 \\
\hline 68 & 834 & 84 & 1262 & 68 & 477 & 63 & 660 \\
\hline 69 & 1640 & 77 & 1214 & 69 & 1057 & 70 & 624 \\
\hline 70 & 1210 & 70 & 1210 & 70 & 624 & 85 & 594 \\
\hline 71 & 627 & 74 & 1193 & 71 & 323 & 65 & 575 \\
\hline 72 & 1653 & 63 & 1145 & 72 & 730 & 77 & 502 \\
\hline 73 & 815 & 65 & 1057 & 73 & 393 & 84 & 486 \\
\hline 74 & 1193 & 85 & 1041 & 74 & 478 & 74 & 478 \\
\hline 75 & 422 & 83 & 956 & 75 & 200 & 68 & 477 \\
\hline 76 & 561 & 61 & 936 & 76 & 180 & 64 & 424 \\
\hline 77 & 1214 & 86 & 854 & 77 & 502 & 86 & 410 \\
\hline 78 & 1882 & 68 & 834 & 78 & 157 & 73 & 393 \\
\hline 79 & 1334 & 73 & 815 & 79 & 702 & 67 & 377 \\
\hline 80 & 478 & 82 & 757 & 80 & 209 & 83 & 349 \\
\hline 81 & 1296 & 64 & 712 & 81 & 711 & 71 & 323 \\
\hline 82 & 757 & 67 & 631 & 82 & 315 & 82 & 315 \\
\hline 83 & 956 & 71 & 627 & 83 & 349 & 80 & 209 \\
\hline 84 & 1262 & 76 & 561 & 84 & 486 & 75 & 200 \\
\hline 85 & 1041 & 80 & 478 & 85 & 594 & 76 & 180 \\
\hline 1986 & 854 & 1975 & 422 & 1986 & 410 & 1978 & 157 \\
\hline
\end{tabular}

(Fonte: Pedrosa e Costa, 1999) 


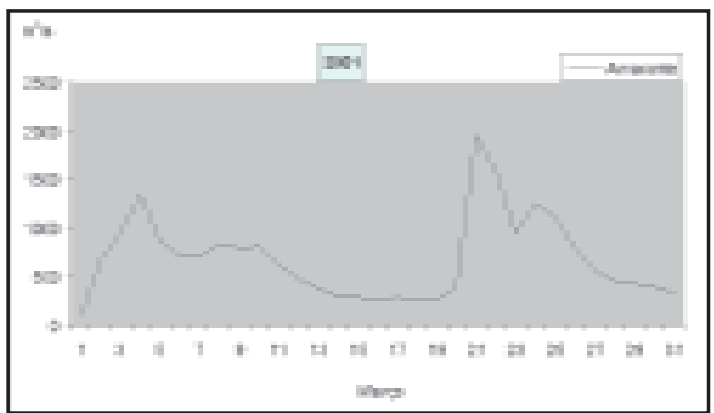

Fig. 4 - Evolução do caudal médio diário durante as cheias de Março de 2001.

(Fonte: Goves e Costa, 2004)

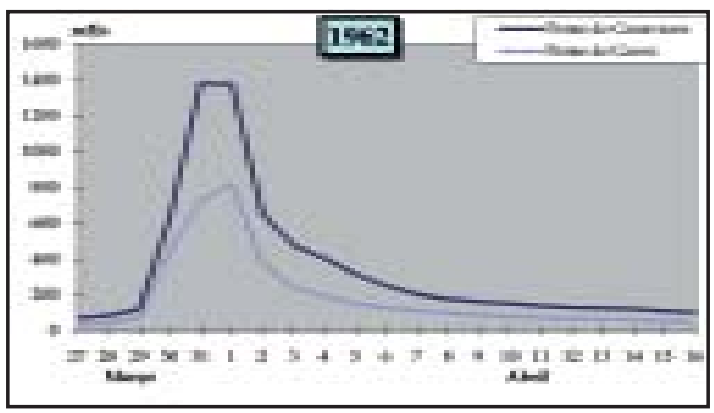

Fig. 5 - Evolução do caudal médio diário durante a cheia de Abril de 1962 (Fonte: Perposa e Costa, 1999).

A doservação dos gráficos relativos à evolução dos caudais médios diários permite inferir da variação do regime do rio e possibilita a distinção entre dbis tipos de cheias - cheias simples e cheias complexas (PAHÉ, 1968). As afluências integrais mensais devem também ser analisadas já que podem ajudar a descrever os diferentes comportamentos hidrológicas das cheias anuis (fig. 6) .

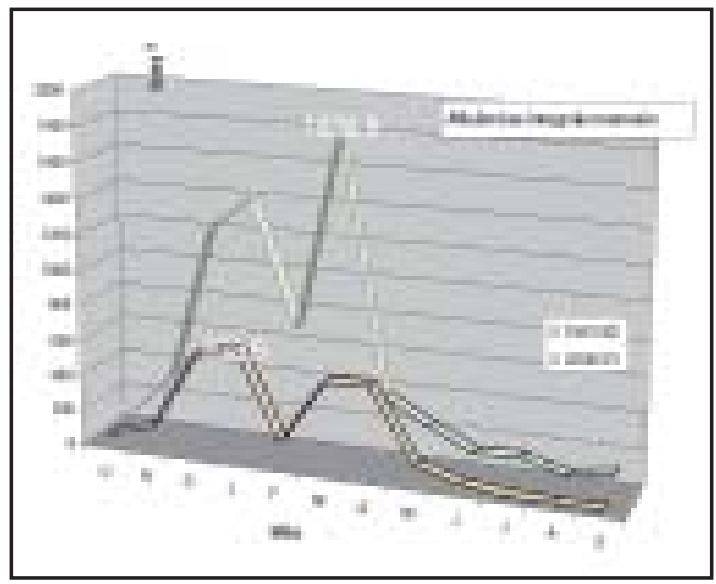

Fig. 6 - Afluências integrais mensais durante os anos hidrológicos de 1962 e 2001 (Fonte: Goves e CoSIA, 2004).

- Registos pluviométricos - Amarante possui numa das freguesias de Amarante (Madalena) uma estação udográfica a funcionar desde 1915 (Qunro IV, fot. 12) .
QUADRO IV - Estação Udográfica de Amarante.

\begin{tabular}{|c|c|c|c|c|c|c|}
\hline CÓDIGO & NoME & ALITTUDE & $\begin{array}{l}\text { TIPODE } \\
\text { ESTACÁAO }\end{array}$ & $\begin{array}{c}\text { ENTRADA } \\
\text { FuNCIONAMENTO }\end{array}$ & ESTADO & FIABILIDADE \\
\hline 06/101G & AMARANTE & $146 \mathrm{~m}$ & UDOGRÁFICA & $\begin{array}{l}13-07-1915 \\
(1403-20066)\end{array}$ & ACTIVA & 15 \\
\hline
\end{tabular}

(Fonte: INAG, 2009)

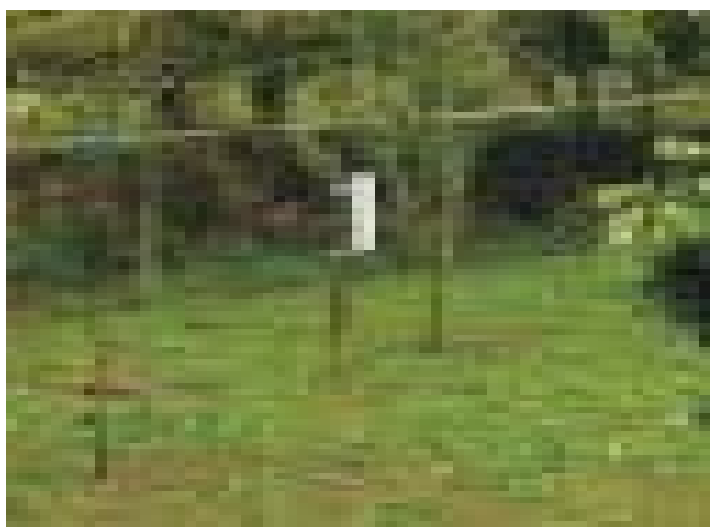

Fot. 12 - Estação udográfica de Amarante (Fonte: INAG, 2009)

Os registos desta estação permitem uma melhor compreensão do regime das cheias já que do conjunto das variáveis climáticas, aquela que mais directamente interessa aos processos de escoamento fluvial é a precipitação (Pmrosa e CoșA, 1999) . A evolução da precipitação diária ao longo das principais inundações revela um comportamento idêntico à variação dos caudais médios diários (figs. 7e 8) .
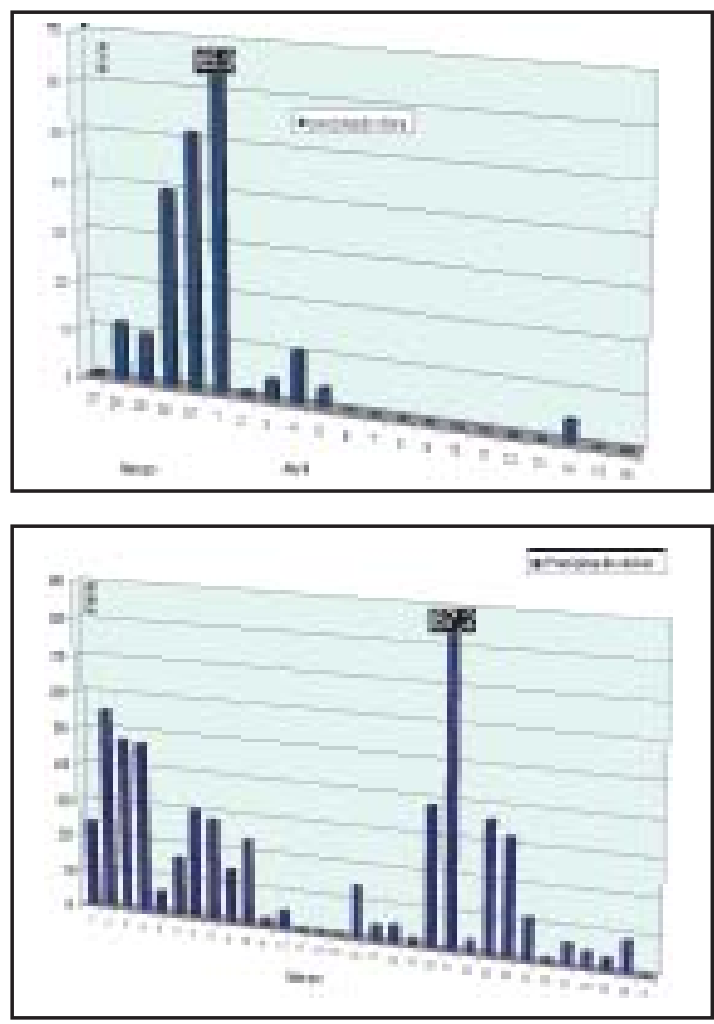

Figs. 7 e 8 - Precipitação diária durante a cheia de Abril de 1962 (Fonte: Goves e CosiA, 2004). 
Compreender o comportamento hidrológico de uma cheia implica conhecer as variações sazonais, no decorrer do ano, que são claramente expressas pelas variaçães dos caudais mensais. As afluências integrais mensais podem ajudar a descrever os diferentes comportamentos hidrológicas das cheias. A variação dos quantitativos totais mensais, ao longo do ano, revela-se, muitas vezes, fundamental na compreensão da amplitude revelada pelas cheias (fig. 9) .

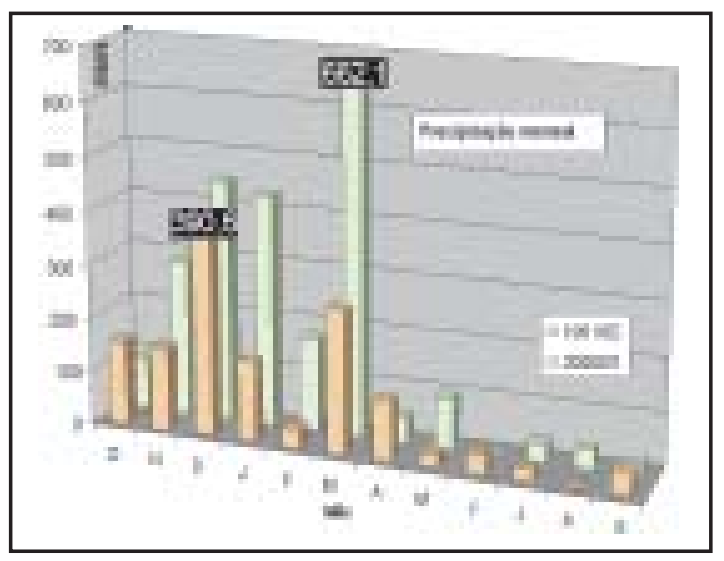

Fig. 9 - Variação mensal da precipitação durante os anos pluviométricos de 1962 e 2001 (Gaves e Costa, 2004)

\section{Informaçães da Protecção Civil}

O Plano Municipal de Fmergência deve assumir neste contexto um papel importante, quer na ident ificação das factores de risco e del imitação das áreas de vulnerabilidade, quer na definição do organigrama da protecção civil ao nível local. As cheias e imundações são aqui referenciadas como "factores de risco" (?) o que determina a identificação dos leitos dos cursos de água e zonas ameaçadas no concelho, no troço a jusante de Fridão até à Ponte de São Gonçalo deve ser tomado como cota máxima de cheia o valor 71 metros e a jusante da Ponte de São Gonçalo e até ao limite do concelho a cota máxima é de 70,5 metros (Goves e Costa, 2004) .

Os relatórios de ocorrência das Bonbeiros locais são também importantes fontes de informação, nomeadamente na parte que diz respeito à descrição da cheia. Veja-se o exemplo do relatório de ocorrência dos BV de Amarante para o dia 21 de Março de 2001 que relata uma intervenção que se iniciou às 15 horas e 16 minutos, tendo terminado 15 horas depois, no dia seguinte, onde refere que "..Foi este conpo de bombeiros alertado. . . para o crescimento anormal do rio Tâmega. Para o local deslocaram-se 4 viaturas, 28 homens e 2 barcos. A nossa actuação baseou-se no apoio que prestamos aos moradores do largo Conselheiro António Cândido e da nua 31 de Janeiro, na evacuação de pessoas e bens, conforme o caudal do rio ia aumentando. O ponto alto da cheia aconteceu no início do dia 22, atingindo nessa altura a nua António Cameiro. Foi considerada a maior cheia dos últimos 100 anos. No dia 22 procedemos a uma vistoria das nuas mais atingidas e verificamos que a maior parte dos estabelecimentos comerciais estavam seriamente danificados, principalmente os da nua 31 de Janeiro" (Goves e Costa, 2004) .

\section{A carta das zonas inundáveis}

A elaboração de uma carta de zonas inundáveis envolve um conjunto de estudbs e análises especcíficas, enquadradas genericamente no campo dos estudos hidrológicos, em que a análise das condições hidrológicas é efectuada tendo em conta as características morfológicas das zonas diferenciadas da respectiva área em análise.

Fundamental na compreensão da área inundada da cidade de Amarante, está a definição dos factores de maior impacto na sua extensão. Aspectos como as curvaturas pronunciadas do rio imediatamente a montante, originadas por razões tectónicas, bem como a ocupação do leito pela extensa ínsua dos Frades, com cerca de 400 metros de extensão e a Praia do Areal, são, semaívida, factores físicos importantes na génese cas cheias, a nível local (fig. 10) .

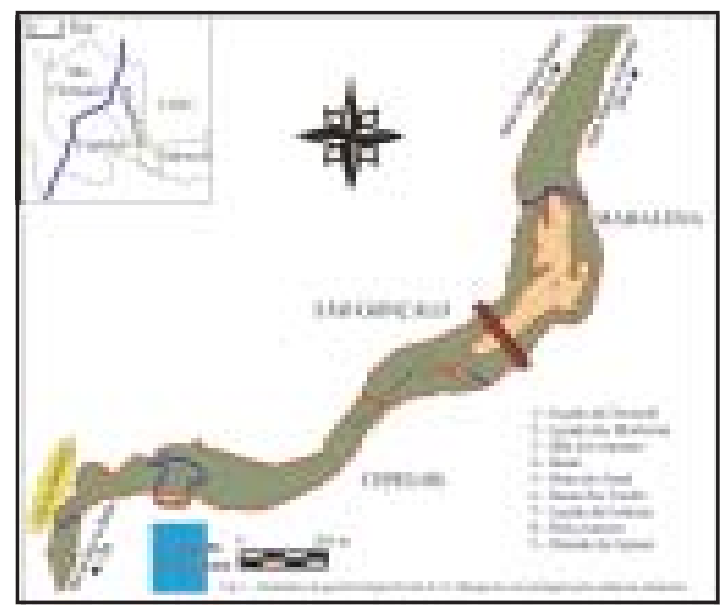

Fig. 10 - Elementos da gecmorfologia fluvial local (Fonte: CosIA, 2002).

autros factores, mas de ordem humana, devem também ser referenciadbs, principalmente o estrangulamento do rio, provocado pela ocupação urbana do leito de cheia, ar o assentamento dos pi lares das pontes Nova (a montante, fot. 13) e de Sáo Gonçalo (principalmente esta, situada a jusante, fot. 14) mo leito do rio.

Neste contexto, e tendb em conta os factores referenciados, toma-se necessária a elaboração de perfis transversais de pormenor, que permitam visual izar o vale fluvial nestas diferentes seç̧ões do rio. 


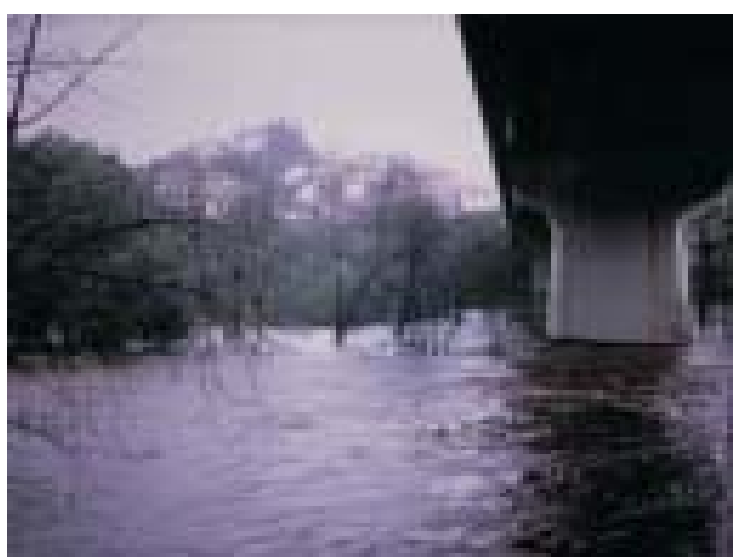

Fot. 13 - Pilares da Ponte Nova durante a cheia de 2001.

o grau de exposição

O Risco de Cheia (RC) é o resultadb da interacção entre:a ameaça de crise - AA - (a probabilidade de ocorrência física) , o grau de exposição de uma comunidade - GE - (a maior ou menor proximidade das linhas de água) e a sua vulnerabilidade - V- (grau de preparação para acidentes, diminuição do risco através da redução da vulnerabilidade) . A medição da exposição dever-se-á efectuar através de parâmetros quant itativos: $-n^{\circ}$ de habitantes, tipo e $\mathrm{n}^{\circ}$ de actividades económicas potencialmente afectadas. Ograu de exposição, quantificadb a partir dos parâmetros enunciados em função de valores estabelecidos (Qunro V), é depois avaliado numa escala qualitativa (Qmiro VI) .

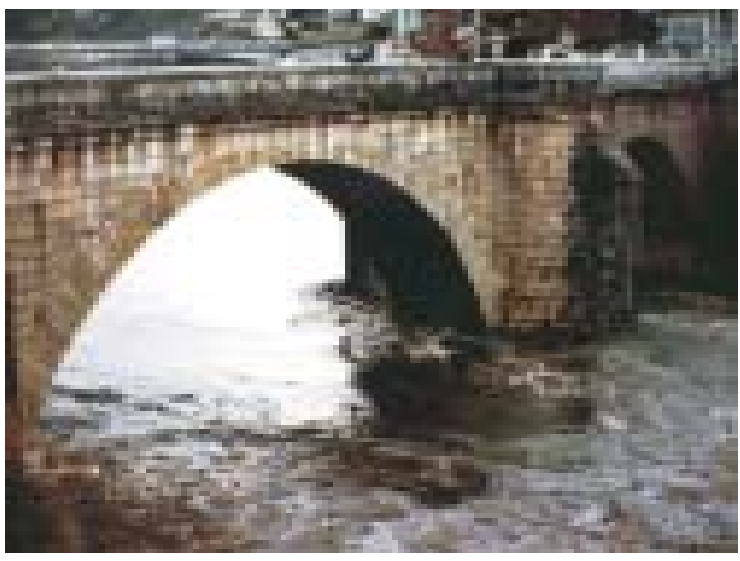

Fot. 14 - Pilares da Ponte de São Gonçalo durante a cheia de1995.

A área afectada

A área urbana atingida pelas inundações em Amarante situa-se na margem esquerda, ao longo da nua 31 de Janeiro, Jardim Amadeu Souza Cardozo e Largo Conselheiro António Cândido, enquanto na margem direita fica apenas submerso o piso inferior do Mercado Municipal (fot. 15) .

Populaçães, actividades e patrimánio afectados

Um dos indicadores a ter em conta para a definição do grau de exposição é a população afectada. A principal área unbana inundada integrase no centro histórico de Amarante, com graves problemas no que respeita à sua ocupação humana.

Qundro V - Indicadores a ter em conta no grau de exposição

\begin{tabular}{|c|c|c|c|}
\hline & \multirow{2}{*}{\multicolumn{3}{|c|}{ 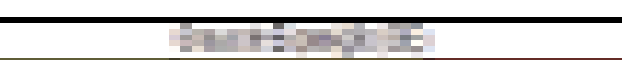 }} \\
\hline & & & \\
\hline 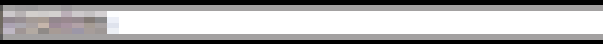 & $=$ & +2 & $5=$ \\
\hline 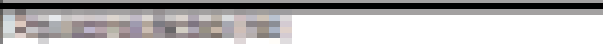 & $=$ & 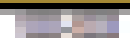 & $=$ \\
\hline & $\bar{E}$ & $=$ & + \\
\hline 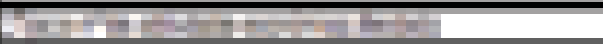 & $-=$ & 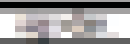 & 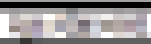 \\
\hline & E & 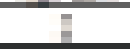 & I \\
\hline 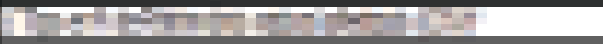 & then & 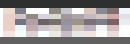 & $=x^{2}=-1=$ \\
\hline & 1 & $=$ & $=$ \\
\hline 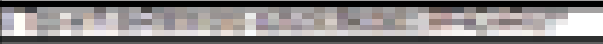 & + & $+=$ & 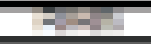 \\
\hline & +1 & $=$ & Tr \\
\hline 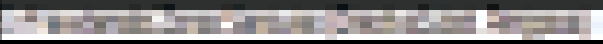 & 1 & $=$ & t \\
\hline 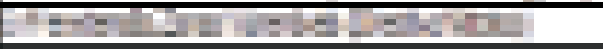 & 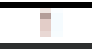 & E & E \\
\hline
\end{tabular}

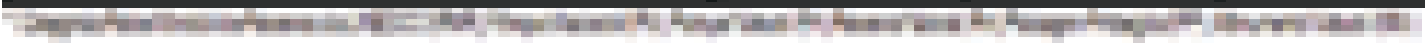

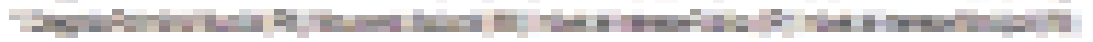

(INAG, 2009)

QARRo VI - Avaliação final do grau de exposição.

\begin{tabular}{|c|c|}
\hline Ana ajad Find & Brese de Enos:ar \\
\hline Eang & rferisab \\
\hline DEda & Erte Be 14 \\
\hline$-\mathrm{NE}$ & Superora 14 \\
\hline
\end{tabular}

(INAG, 2009)
Temos assim um reduzido número de habitantes residentes, constituído por uma população envelhecida, resultado do abandono das gerações mais jovens e associada à falta de condições de habitabilidade (fot. 16) e uma população móvel e volátil, constituŕda por classes mais desfavorecidas e, muitas vezes, por imigrantes. 


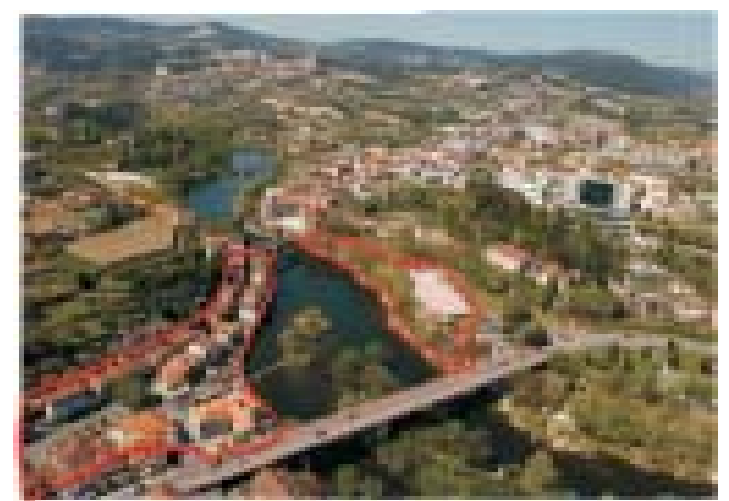

Fot. 15 - Área do centro urbano de Amarante afectada pelas maiores inundaçães (elaboração própria) .

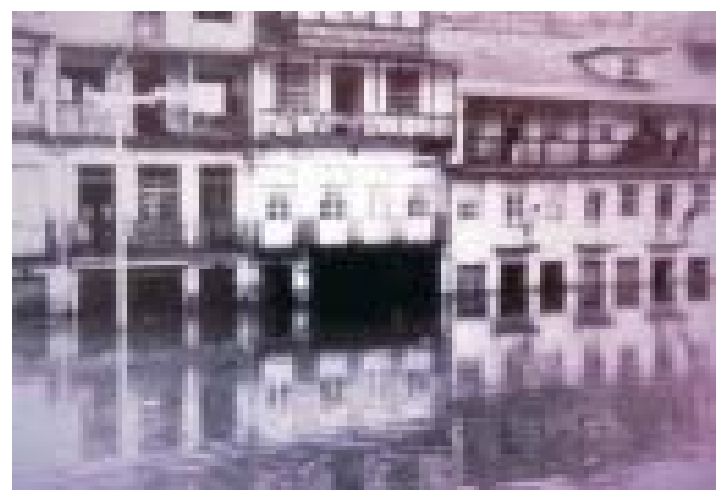

Fot. 16 - Aspecto das habitações do largo Conselheiro António Cândido durante a cheia de 1939.

Toma-se assim importante actualizar os dados relativos à população local, quer a residente, quer a presente, a partir deumlevantamento in situ, referindb aqui o papel que poderão ter os presidentes das duas juntas de freguesia mais afectadas pelas cheias na margem esquerda, Cepelos e Madalena.

No que se refere às actividades económicas, é nítido o predomínio do sector comercial associado à restauração e afins. Quase todas as casas comerciais possuem caves, anexos, arrecadações ou armazém e varandas, que, emperíodb de cheia, são os primeiros espaças a ser inumdadas (fots. 17 e 18) .
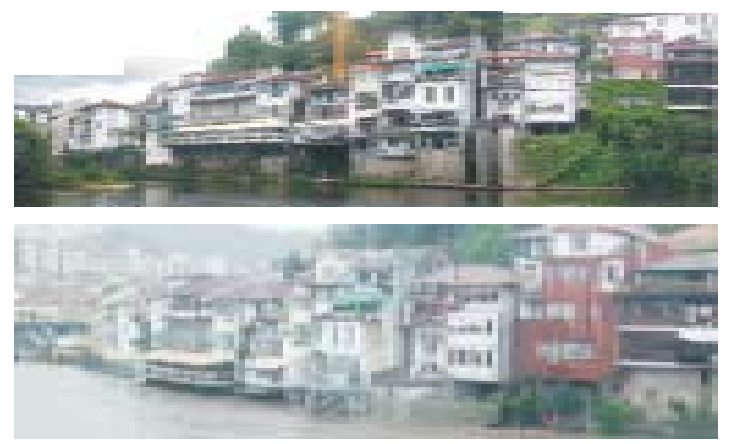

Fots. 17 e 18 - Aspecto das casas situadas ao longo da rua 31 de Janeiro na margem esquerda situadas do rio Tâmega, antes e durante as cheias de 2001.
Também existem serviços, nomeadamente, ligados à actividades financeira e seguradoras, bem como ao sector dos transportes públicos e venda de combustíveis (fots. 19e20) .

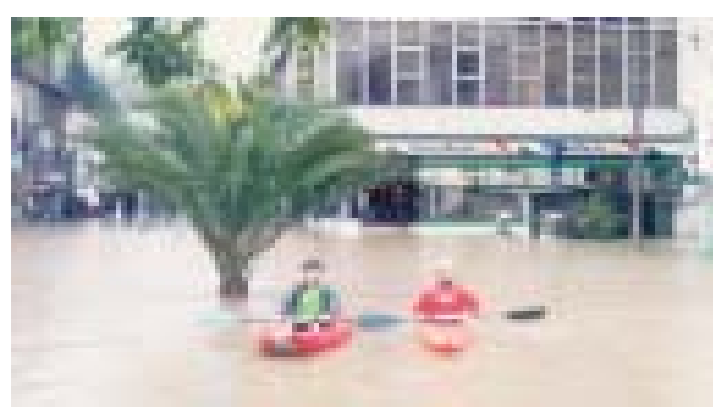

Fot. 19 - Sectores ligados aos serviças e transportes afectados durante a cheia de 2001.

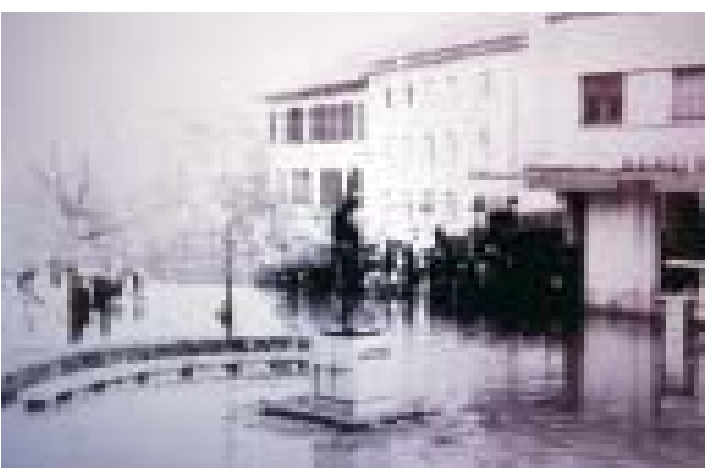

Fot. 20 - Sectores ligados aos serviços e transportes afectados durante a cheia de 1962.

Além dos fluxos relacionados com a acessibilidade e mobilidade serem praticamente inviabilizadbs durante as inundações, o que se traduz nos prejuízos decorrentes da paragem destas actividades económicas, outros impactes, por exemplo, ambientais, devem ser considerados, dada a existência de bombas de gasolina e duma rede de saneamento básico bastante antiquada neste local.

Quanto ao património construído, destaca-se a Ponte de São Gonçalo (monumento nacional, Dec. de 16.06.1910, DG 136, de 23-06-1910), que chegou a sofrer danos resultantes da rotura de uma das pedras de anhal de um dos 2 pilares centrais, durante as cheias de 2001 (fot. 21) .

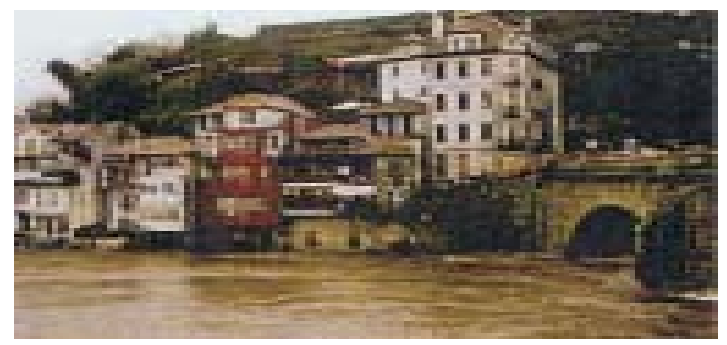

Fot. 21 - Efeito da cheia de 2001 sobre o pilar da Ponte de São Gonçalo (Fot. INAG, 2009) . 


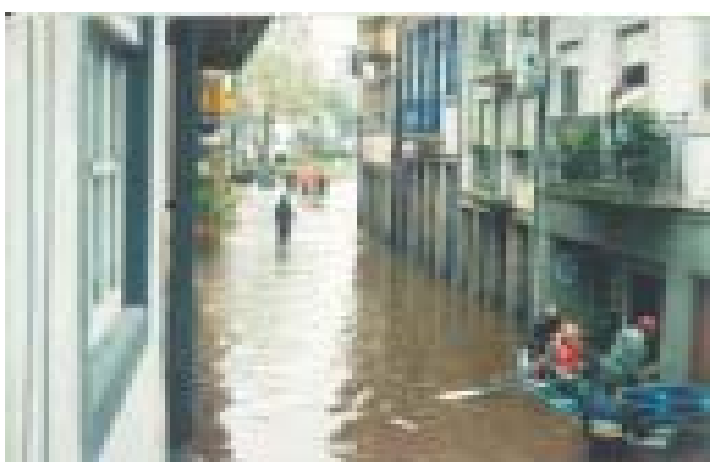

Fot. 22 - Centro histórico durante a cheia de 22 de Março de 2001.

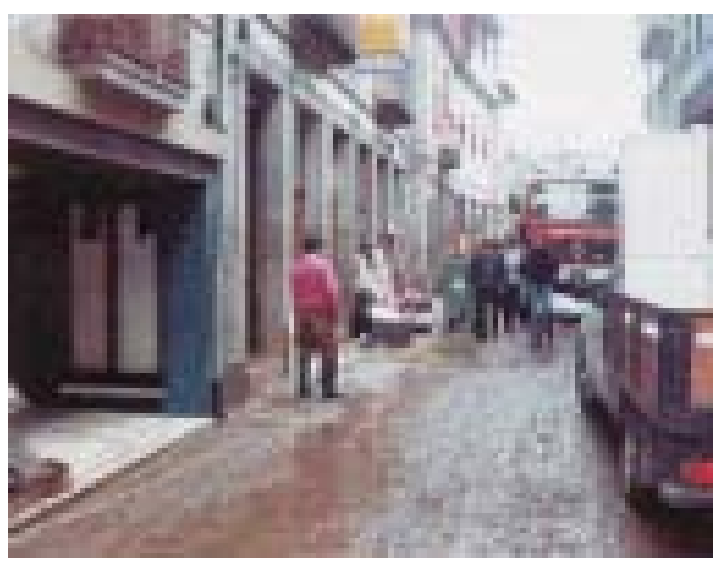

Fot. 23 - Centro histórico após a cheia de 22 de Março de 2001.

O centro Histórico de Amarante está classificado como Imóvel de Interesse Público (Dec. 735/74, DG 297, de 21-12-1974) , integrando várias nuas, entras as quais a Rua 31 de Janeiro e o Largo Conselheiro António Cândido (fots. 22 e 23).

No que respeita ao património natural, não existem no local áreas classificadas ou sob algum estatuto de protecção natural. No entanto, a área ribeirinha eas i lhas locais já forcm, por várias vezes, dojecto de estudo e tentativa de classificação no IPPAR, a partir de iniciativas autárquicas.

As margens apresentam características morfológicas e biogeográficas distintas. Na margem esquerda, com declives mais suaves, são visíveis algumas mandhas de retalhos de aluviões actuais. A margem direita, voltada. aos quadrantes do sul, de perfil mais irregular, é aproveitada para a prática agrícola, nomeadamente, nas encostas, ande são plantados os vinhedos.

Săo diversificados os elementos naturais presentes ao longo das margens: rochas nuas, matas ribeirinhas, matos e culturas arbustivas, manchas de floresta mista, áreas agrícolas. Subsistem ainda alguns núcleas de vegetação ribeirinha autóctone, além de uma fauna própria de ecossistemas fluviais. A hidrodinâmica fluvial também intervém no desenvolvimento de algumas formas relacionadas com processos de sedimentação, que se manifestam de duas formas diferentes no troço urbano do Rio Tâmega: as ilhas (ou ínsuas, como são designadas localmente) e as praias fluviais. O exemplo mais espectacular é representado pela Ínstra dos Frades, uma il ha de contomos irregulares, situada entre o açude da Feitoria e a Ponte Nova.

As cheias de Março de 2001 levaram esta Ínsua à sua completa degradação física e ambiental (fotos 24 e 25) , o que motivou o vereador responsável pela Protecção Civil a solicitar, junto da Companhia Portuguesa de Prooução de Electricidade, S. A. (proprietária) "..autorização para uma intervenção de carácter ambiental numa ínsua atingida pelos efeitos das últimas cheias, operações de limpeza, corte de árvores derrubadas e recuperação de plantas e plantação, regularização de terras.." , tendb dbtido parecer favorável (Goves e CosIA, 2004) .
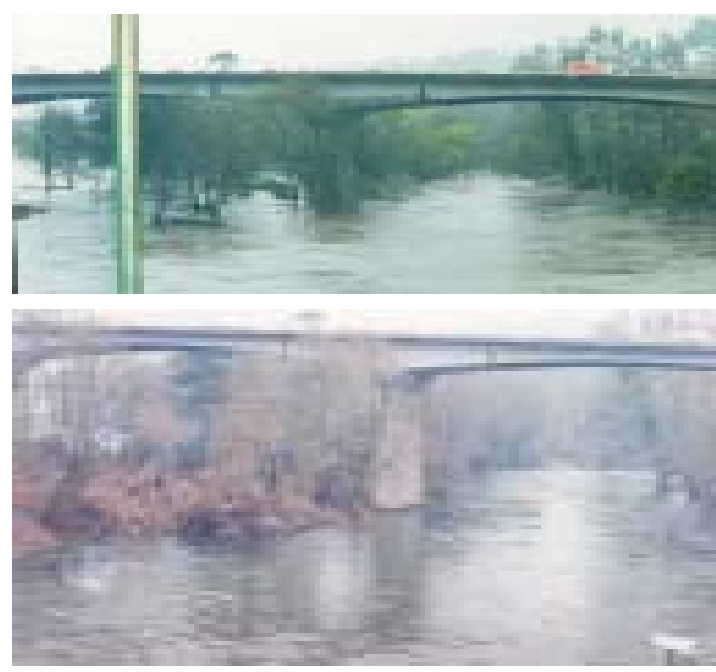

Fots. 24 e 25 - Aspectos da destruição provocada pelas cheias de Março de 2001 na Ínsua dos Frades

Os impactes das cheias desse ano também obrigaram os responsáveis autárquicos e os BVA a intervir na reaperação das margens e das i lhas fluviais.

\section{Notas canclusivas}

ADirectiva 2007/60/EC relativa à gestão do risco de inundações, tempor dojectivo reduzir o risco e as consequências negativas das inundações na União Europeia. Trata-se, sem dúvida, duma directiva que revela um grande avanço no campo da avaliação prel iminar das cheias, através de várias metooblogias:

- a cartografia de risco;

- a descrição das cheias que ocorreram no passado;

- a descrição dos planos de desenvolvimento e 
de ocupação do solo futuros com implicação no risco e dheias;

- a caracterização da probabilidade de ocorrência de cheias tendo em conta as mudanças climáticas e de uso do solo;

- a previsão das consequências estimadas das dheias futuras na segurança (saúde) de pessoas, do ambiente e das actividades económicas.

Neste sentido, é considerada premente a elaboração dos planos de gestão do risco de inundação à escala de bacia hidrográfica. Estes planos apontam objectivos claros na redução e gestão do risco de cheia, na análise dos riscos, na definição do nível de protecção e na ident ificação e implementação de medidas de prevenção sustentável. Trata-se de um instrumento muito importante de planeamento e de comunicação, que também visa aumentar a sensibilização do público at ravés da disponibil ização dos planos de gestão do risco, do ordenamento do território eplanos de energênciae, assim, justificar os processos de decisão. A informação e participação do püblico tomar-se-á fundamental. Para isso, serão colocados à sua disposição o estudo preliminar do risco de inundação e os mapas de risco, por forma a assegurar uma participação activa de todas as partes interessadas na produção, reexame e actual ização das planos de gestão das riscos de inundação.

As cheias em Amarante são fenómenos que sempre marcaram e continuarão a marcar a vivência do centro histórico da cidade. Conviver com as cheias implica, sem dúvida, uma nova forma de abordagem deste tipo de fenómeno e por isso assumir e compreender o risco - uma nova fil losofia de risco, saber gerir as incertezas, promover a gestão integrada e garantir a sustentabilidade. Trata-se sem dívida duma nova visão onde a responsabilidade da autarquia, do Estado e do cidadão são parti lhadas.

\section{Referências bibliográficas}

CosiA, F. S. (1998) - A importância dos processos morfogenéticos actuais no ordenamento urbano - O caso de Amarante. Dissertação de Mestrado, Faculdade de Letras da Universidade do Porto, Porto.

CosiA, F. S. (1998) - "O rio e a cidade: contributo para o estudo da qualidade ambiental do rio Tâmega na sua passagem pelo centro urbano de Amarante" . Revista da Faculdade de Letras Ceografia, I Série, Vol. XV/XVI, Universidade do Porto, Porto, p. 79-95.

CosIA, F. S. (1998) - "A geografia no contributo à gestão e ao planeamento físico da cidade - 0 caso de Amarante". InforGeo, 12 \& 13, "A interdisciplinaridade na Geografia Portuguesa: novos e velhos desafios", Ediçães Colibri e Associação Portuguesa de Geógrafos, Lisbooa, p. $275-280$.

CosIA, F. S. (2002) - "A qualidade ambiental do Rio Tâmega na sua passagem pela cidade de Amarante - Breve retrospectiva", in Livro de Resumo de Poster's, $6^{\circ}$ Congresso da Água, de 18 a 22 de Março de 2002, Porto, p. 65-66.

CostA, F. S. (2002) - "As grandes cheias do Rio Tâmega (o caso do período 1960-1986", in Liviro de Resumo de Poster's', $6^{\circ}$ Congresso da Água, de 18 a 22 de Março de 2002, Porto, p. 67-69.

Goves, S. A. L. ; COSIA, F. S. (2004) - "As cheias urbanas em Amarante - o caso da cheia do rio Tâmega em 2001". Actas do $7^{\circ}$ Congresso da Água, Laboratório Nacional de Engenharia Civil, Lisboa, 8 a 12 de Março 2004, Li.sboa, 8 a 12 de Março 2004, 14 p.

D.G.R.A.H. (1986) - Monografias hidrológicas dos principais arsos de áqua de Portugal Continental. Iisboa.

EGF (1981) - Análise de impactes ambientais da barragem do Torrão - $1^{2}$ fase. EDP, Lisboa.

FAcrins, L. (1990) - "La théorie du risque". Le Risque et la crise, Foundation for Intemacional Studies, Malta, p. 53.

FERANDES, A. P. (1960) - "O vale de fractura de Fomelo - Padronelo - Amarante" . Boletim ob Museu e Laboratório Mineralógico e Geológico da Faculdobde de Ciências, 8 (2) , Lisboa, p. 139-147.

MA / DRARN-NORTE (1996) - Atlas de Recursos hídricos db Nbrte. Vol. I, Porto.

MA/INAG (1995) - Recursos hídricos de Portugal continental e suautilização. Vol. I I II, Iisboa.

MirRanA, A. P. C. (1997) - Adeus Tâmega, Adeus Rio, Adeus Amarante. Amarante.

Perrosa, A. S. ; CosiA, F. S. (1999) - "As cheias do rio Tâmega. O caso da área urbana de Amarante", Territorium, 6, Coimbra, p. 49-78.

\section{Fontes}

http: //eurlex.europa.eu/LexUriserv/ LexUriServ.db?uri=QJ:L:2007:288:0027:0034:PI:IDF

http://www.maraoonline.com/MARAO_2009/ MARAO_online/MARAO_online.html 